\title{
Anesthesia Management of Simultaneous Cesarean Section and Valve Replacement: A Tight-rope Walk Twice!
}

\author{
${ }^{1}$ Ruchi A Jain, ${ }^{2}$ Shakuntala Basantwani, ${ }^{3}$ Surabhi Nellore, ${ }^{4}$ Bharati A Tendolkar
}

\begin{abstract}
Background: Rheumatic valvular stenosis is the most common valvular heart disease which is encountered in pregnant patients in our country. Combination of severe mitral or aortic stenosis (AS) and physiological changes that accompany pregnancy amplifies problems.
\end{abstract}

Case report: Two patients with severe rheumatic valve stenosis underwent simultaneous cesarean section (CS) and valve replacement (VR) surgeries. Heart rate (HR) control with diltiazem was required in one patient who was in atrial fibrillation $(\mathrm{AF})$. Anesthesia was induced with etomidate and rocuronium. Cesarean section was performed followed by VR.

Conclusion and clinical significance: Management of anesthesia for such cases is a challenge, as there is a risk of worsening cardiac failure at multiple stages, increasing maternal and fetal morbidity and mortality. The conventional high-dose opioid-based anesthesia strategy followed for VR in stenotic lesions may cause neonatal respiratory depression requiring ventilatory support. A tight balance between maintaining maternal hemodynamics, uterine blood flow, and fetal oxygenation is required for good maternal and fetal outcomes.

Keywords: Anesthesia, Aortic stenosis, Cesarean section, Mitral stenosis, Rheumatic heart disease.

How to cite this article: Jain RA, Basantwani S, Nellore S, Tendolkar BA. Anesthesia Management of Simultaneous Cesarean Section and Valve Replacement: A Tight-rope Walk Twice! Res Inno in Anesth 2018;3(1):22-25.

Source of support: Nil

Conflict of interest: None

\section{BACKGROUND}

Prevalence of heart disease in pregnancy ranges from 0.3 to $3.5 \%{ }^{1}$ As the severity of heart disease increases, the cardiac complication rate increases. ${ }^{2}$ Mitral stenosis (MS) is the most common lesion in rheumatic heart disease (RHD), whereas AS is a relatively rare lesion. Patients with

\footnotetext{
${ }^{1}$ Assistant Professor, ${ }^{2}$ Associate Professor, ${ }^{3}$ Consultant ${ }^{4}$ Professor and Head

${ }^{1,2,4}$ Department of Anesthesia, Lokmanya Tilak Municipal General Hospital and Lokmanya Tilak Municipal Medical College, Mumbai, Maharashtra, India

${ }^{3}$ Department of Anesthesia, MGM New Bombay Hospital, Navi Mumbai, Maharashtra, India

Corresponding Author: Ruchi A Jain, Assistant Professor Department of Anesthesia, Lokmanya Tilak Municipal General Hospital and Lokmanya Tilak Municipal Medical College Mumbai, Maharashtra, India, e-mail: ruchiajain@gmail.com
}

severe stenotic valve lesions do not tolerate well the physiological changes of pregnancy and the chance of cardiac failure increases from the second trimester onward. Timely termination of pregnancy may help reduce this additional burden on the heart. However, refractory cardiac failure may ensue and emergency CS and VR remain the only choice in such a situation. The anesthetic management of combined surgery in the same sitting has many challenges as this report of two cases reveals.

\section{CASE REPORT}

We present a report of two patients who underwent simultaneous CS and VR surgery. The clinical details of both patients are given in Table 1 .

\section{Case 1}

A 23-year-old primigravida, diagnosed case of severe MS, with valve area of $1.1 \mathrm{~cm}^{2}$, severe pulmonary artery hypertension [mean pulmonary artery pressure (PAP) of $52 \mathrm{~mm} \mathrm{Hg}$ ], AF and left atrium (LA) thrombus (28 mm $\times 28 \mathrm{~mm}$ ) was admitted in the 32nd week of pregnancy for safe confinement with a plan for elective CS. She was receiving metoprolol, furosemide, digoxin, and warfarin. Warfarin was replaced by unfractionated heparin. Betamethasone was started for fetal lung maturity. However, within 3 days of admission, she developed orthopnea. Physical examination revealed HR of 120 beats/minute irregularly irregular, blood pressure (BP) of 146/96 mm Hg, respiratory rate of 36 to $40 /$ minute, and bilateral crepitation. She was ventilated with continuous positive airway pressure (CPAP) of $10 \mathrm{~mm} \mathrm{Hg}$ and fraction of inspired oxygen $\left(\mathrm{FiO}_{2}\right)$ 0.9. Her oxygen saturation $\left(\mathrm{SpO}_{2}\right)$ was $95 \%$ and arterial blood gas revealed $\mathrm{pH}$ 7.29, partial pressure of oxygen $88 \mathrm{~mm} \mathrm{Hg}$, and partial pressure of carbon dioxide $27 \mathrm{~mm} \mathrm{Hg}$. Two-dimensional echocardiography (2D-ECHO) revealed persistent $\mathrm{AF}$, worsening of MS (valve area $0.7 \mathrm{~cm}^{2}$ ), increase in size of clot $(47 \mathrm{~mm} \times 28 \mathrm{~mm})$, and pericardial effusion. Despite aggressive medical management, progressive refractory cardiac failure ensued. After discussion with the cardiologists, cardiac surgeons, obstetricians, anesthesiologists, and neonatologists, it was decided to do an emergency CS followed by mitral valve replacement (MVR) in the same sitting. 
Anesthesia Management of Simultaneous CS and VR

Table 1: Clinical information of both patients

\begin{tabular}{lll}
\hline Parameter & Case 1 & Case 2 \\
\hline Age & 23 years & 25 years \\
Parity & Primigravida & Second gravida \\
Diagnosis & Rheumatic heart disease & Rheumatic heart disease \\
Weeks of gestation & 32 & 38 \\
History & DOE grade II progressed to grade IV, palpitations & DOE grade III \\
Examination findings & HR: $120-140 / \mathrm{min}$ irregularly irregular & HR: $70 / \mathrm{min}$ regular \\
& BP: $146 / 96 \mathrm{~mm} \mathrm{Hg}$ & BP: $110 / 70 \mathrm{~mm} \mathrm{Hg}$ \\
& RR: $35-40 / \mathrm{min}$ & RR: $20 / \mathrm{min}$
\end{tabular}

Two-dimensional echo findings

Preoperative investigations

Obstetric ultrasonography Medications (Reason for change of plan)

Planned mode of delivery Admission for safe confinement followed by elective LSCS after fetal maturity

Reason or change of plan Cardiac failure

AF, MVA $0.7 \mathrm{~cm}^{2}$, calcified mitral valve leaflets, left atrial clot, mean PAP $52 \mathrm{~mm}$ Hg, LVEF 50\%, pericardial effusion, mild TR

$0.8 \mathrm{mg} / \mathrm{dL}$, aPTT $>2$ times control

Intrauterine growth retardation

Metoprolol, furosemide, digoxin, warfarin

DOE: Dyspnea on exertion; RR: Respiratory rate; MVA: Mitral valve area; LVEF: L time; INR: International normalized ratio; LSCS: Lower segment cesarean section

\section{Case 2}

A 25-year-old second gravida with history of balloon mitral valvotomy for MS and CS in previous pregnancy was admitted for elective CS in view of heart disease. The 2D-ECHO revealed severe AS with peak and mean gradient of 79 and $45 \mathrm{~mm} \mathrm{Hg}$ respectively. After multidisciplinary discussion, it was decided to do elective CS and aortic valve replacement (AVR) simultaneously.

\section{Clinical Management}

After written informed consent, both patients were prepared for surgery. Monitoring included 5-lead electrocardiogram, pulse oximetry, noninvasive BP, Entropy ${ }^{\circledR}$, urine output, and fetal heart rate (FHR). The first patient was transferred to the cardiac operation theater in propped up position with CPAP. She was extremely anxious with HR of 150 to 160 beats/minute. Diltiazem $12.5 \mathrm{mg}$ was given titrated to reduce the HR to around $100 / \mathrm{min}$. Midazolam $0.5 \mathrm{mg}$ and fentanyl $50 \mu \mathrm{g}$ were given for anxiolysis. Due to orthopnea, right internal jugular vein was cannulated in propped up position and femoral arterial line was taken under local anesthesia. In the second patient, invasive lines were secured in supine position. The FHR remained between 120 and 130 beats/minute. The operating table was given a left tilt to prevent inferior vena cava compression. Further management was similar in both patients. Etomidate $0.3 \mathrm{mg} / \mathrm{kg}$ and rocuronium $1.2 \mathrm{mg} / \mathrm{kg}$ were administered intravenously for rapid sequence intubation. Both patients were ventilated with $100 \%$ oxygen, maintaining normocarbia till the baby was delivered, which took 7 and 13 minutes respectively.
The Apgar score of the first baby was 3 and 6 at 1 and 5 minutes respectively. The baby was intubated and ventilated. The baby could be extubated after 15 minutes due to clinical improvement. The Apgar score of the second baby was 3 and 5 at 1 and 5 minutes. The baby was intubated and required ventilator support for 6 hours.

After baby delivery, both patients were ventilated using air: oxygen maintaining $\mathrm{FiO}_{2}$ 0.7. Midazolam $1 \mathrm{mg}$ and fentanyl $150 \mu \mathrm{g}$ were given. Anesthesia was maintained with fentanyl 5 to $10 \mu \mathrm{g} / \mathrm{kg} /$ hour and vecuronium $0.08 \mu \mathrm{g} / \mathrm{kg} /$ minute maintaining Entropy ${ }^{\circledR}$ between 40 and 60 . Slow oxytocin infusion was started. Furosemide $20 \mathrm{mg}$ was administered. Abdomen was closed after thorough hemostasis. Fentanyl $100 \mu \mathrm{g}$ was repeated prior to sternotomy. After instituting cardiopulmonary bypass (CPB), MVR was performed in the first patient and AVR in the second patient was performed using a bio prosthetic valve, maintaining a perfusion pressure of 50 to $60 \mathrm{~mm} \mathrm{Hg}$. The details of $\mathrm{CPB}$ are mentioned in Table 2. Both patients were weaned

Table 2: Parameters during cardiopulmonary bypass

\begin{tabular}{lll}
\hline Operative course & Case 1 & Case 2 \\
\hline Total CPB time & 1 hour 20 min & 2 hours 25 min \\
Aortic clamp time & $55 \mathrm{~min}$ & 1 hour 45 min \\
Furosemide & $30 \mathrm{mg}$ & $20 \mathrm{mg}$ \\
Ultrafiltrate & $600 \mathrm{~mL}$ & $1000 \mathrm{~mL}$ \\
Urine output & $500 \mathrm{~mL}$ & $750 \mathrm{~mL}$ \\
Total intravenous & $500 \mathrm{~mL} 6 \% \mathrm{HES}$ & $500 \mathrm{~mL} \mathrm{6 \%} \mathrm{HES}$ \\
fluid & $250 \mathrm{~mL}$ saline & $500 \mathrm{~mL} \mathrm{RL}$ \\
& 1 unit PRC & 1 unit PRC \\
\hline
\end{tabular}

HES: hydroxyethyl starch, RL: Ringer lactate, PRC: packed red cells 
Table 3: Hemodynamic parameters

\begin{tabular}{|c|c|c|c|c|c|c|c|}
\hline & Preoperative & Postinduction & $\begin{array}{l}1 \text { min after } \\
\text { delivery }\end{array}$ & $\begin{array}{l}3 \text { min after } \\
\text { delivery }\end{array}$ & $\begin{array}{l}5 \text { min after } \\
\text { delivery }\end{array}$ & $\begin{array}{l}10 \text { min after } \\
\text { delivery }\end{array}$ & Post-CPB \\
\hline \multicolumn{8}{|l|}{ Case 1} \\
\hline HR (beats/min) & 150 & 110 & 98 & 110 & 100 & 95 & 98 \\
\hline MAP (mm Hg) & 110 & 100 & 90 & 80 & 78 & 70 & 70 \\
\hline CVP $\left(\mathrm{cm}\right.$ of $\left.\mathrm{H}_{2} \mathrm{O}\right)$ & 14 & 14 & 14 & 18 & 20 & 18 & 12 \\
\hline $\mathrm{SpO}_{2} \%$ & 95 & 98 & 98 & 95 & 93 & 97 & 99 \\
\hline ECG & AF & AF & AF & AF & $\mathrm{AF}$ & AF & NSR \\
\hline \multicolumn{8}{|l|}{ Case 2} \\
\hline HR (beats/min) & 80 & 92 & 88 & 78 & 70 & 74 & 90 \\
\hline MAP (mm Hg) & 100 & 96 & 88 & 86 & 80 & 90 & 80 \\
\hline $\operatorname{CVP}\left(\mathrm{cm}\right.$ of $\left.\mathrm{H}_{2} \mathrm{O}\right)$ & 8 & 9 & 9 & 10 & 12 & 10 & 9 \\
\hline $\mathrm{SpO}_{2} \%$ & 99 & 99 & 99 & 99 & 99 & 99 & 99 \\
\hline ECG & NSR & NSR & NSR & NSR & NSR & NSR & NSR \\
\hline
\end{tabular}

MAP: Mean arterial pressure; CVP: Central venous pressure; $\mathrm{SpO}_{2}$ : Oxygen saturation; ECG: Electrocardiograph; NSR: Normal sinus rhythm; AF: Atrial fibrillation

off CPB. Both the patients required dopamine $3 \mu \mathrm{g} / \mathrm{kg} /$ minute for weaning and adrenaline $0.06 \mu \mathrm{g} / \mathrm{kg} / \mathrm{min}$ was required in the first case. Hemodynamic parameters of the patients, before and after CS and VR, are shown in Table 3 . Furosemide $60 \mathrm{mg}$ and torsemide $20 \mathrm{mg}$ were administered postweaning from $\mathrm{CPB}$ to the first patient. The post- $\mathrm{CPB}$ hemoglobin of both patients was $7 \mathrm{gm} / \mathrm{dL}$; hence, both received one unit of packed red cells each. The patients were electively ventilated and extubated 14 and 16 hours later respectively. No unusual bleeding was encountered in the perioperative period. Inotropes were gradually tapered and stopped. The first patient was started on warfarin, torsemide, metoprolol, diltiazem, and aspirin. The 2D-ECHO on postoperative day 12 showed persistence of AF and reduction of mean PAP to $38 \mathrm{~mm} \mathrm{Hg}$. The patient was discharged on day 22 . The second patient was started on aspirin, warfarin, torsemide, and amiodarone, as she developed AF postsurgery. Postoperative 2D-ECHO revealed reduction in peak and mean pressure gradients across aortic valve to 24 and $14 \mathrm{~mm} \mathrm{Hg}$ and mean PAP of $36 \mathrm{~mm} \mathrm{Hg}$. She was discharged on day 20.

\section{DISCUSSION}

Rheumatic heart disease is the main cause of heart disease in Indian pregnant patients $(88 \%){ }^{3}$ Our patients were classified as stage D valvular heart disease (severe symptomatic MS and severe symptomatic AS respectively) as per the 2014 American Heart Association/American College of Cardiology (AHA/ACC) guidelines for management of patients with valvular heart disease ${ }^{4}$ and were at extremely high risk (class IV) of maternal mortality or morbidity. ${ }^{5}$ Pregnant patients with severe valve stenosis should be monitored in a tertiary care center with a dedicated team of cardiologists, surgeons, anesthesiologists, and obstetricians with expertise in the management of high-risk cardiac patients during pregnancy. ${ }^{5}$ Mitral valve surgery may be considered for patients with severe MS (mitral valve area $<1.5 \mathrm{~cm}^{2}$, stages $C$ and D) who have had recurrent embolic events while receiving adequate anticoagulation. ${ }^{4}$ The AVR is recommended in patients of severe AS with symptoms of heart failure, syncope, exertional dyspnea, angina, or syncope on history or on exercise testing and with mean pressure gradient of $40 \mathrm{~mm} \mathrm{Hg}$ or higher. ${ }^{4}$ The risk of cardiac failure in pregnant patient with heart disease increases from the second trimester onward. Pregnancy is a hypercoagulable state. Despite maintaining prothrombin times 2.0 to 2.5 times the control value, some patients may demonstrate thromboembolic episodes. ${ }^{6}$ In the first patient, steroids had been given for fetal lung maturity cases and in the second, the fetus had reached the period of viability. Hence, it was decided to proceed ahead with CS and MVR/AVR to remove the additional load placed on the heart secondary to the pregnancy.

The following issues have to be considered while planning combined MVR with CS: (1) anesthetic considerations due to severe MS with AF and LA thrombus; (2) increased risk of fetal hypoxia secondary to maternal hypoxia resulting from pulmonary congestion. Neonatal respiratory depression due to transfer of anesthetic drugs across the placenta compounds the problem; (3) worsening of cardiac failure due to autotransfusion from uterus after baby delivery; (4) increased risk of uterine bleeding.

Meticulous control of HR is needed in MS and AS to maintain left ventricular end diastolic volume and, subsequently, cardiac output. Despite digoxin and metoprolol, the first patient's ventricular rate was 110 to 120 beats/minute and anxiety worsened it. Calcium channel blockers are indicated for rate control in pregnancy only when beta-blockers and digoxin are unsuccessful. ${ }^{7}$ Hence, diltiazem was used for rate control. Remifentanil provides cardiovascular stability with minimal side 
effects in neonate. ${ }^{8}$ Low doses of midazolam and fentanyl were given since they have no adverse effect on neonatal outcome and remifentanil was not available. ${ }^{9}$ High dose of fentanyl was found to cause severe neonatal respiratory depression necessitating mechanical ventilation. $^{10}$

Mitral stenosis and AS are low cardiac output states. Most anesthetic agents used for induction result in hypotension which can reduce uteroplacental blood flow. The combined effect of this low cardiac output state and hypotension may adversely affect the neonatal outcome. Other authors have reported the use of thiopentone for induction which causes hypotension and can worsen tachycardia. ${ }^{10-12}$ Also, high dose of fentanyl, when used for induction, can lead to severe neonatal respiratory depression. ${ }^{10}$ Etomidate, which has no effect on the sympathetic nervous system, was used to avoid hypotension. Etomidate has been safely used for induction in pregnant cardiac patients. ${ }^{13}$ Heparinization needed during $\mathrm{CPB}$ increases the risk of uterine bleeding after CS. We did not encounter increased bleeding similar to the findings of other authors. ${ }^{10,12}$

Inhalational anesthetics and inotropes with beta-2 agonist effect cause uterine relaxation which may aggravate bleeding. Potential uterine relaxation by inhalational anesthetics was avoided by using fentanyl infusion for maintenance of anesthesia with additional dose of midazolam after baby delivery. We chose oxytocin infusion as methylergometrine increases systemic and pulmonary vascular resistance. There was an increase in the central venous pressure and peak airway pressure (from 14 to $24 \mathrm{~cm} \mathrm{H}_{2} \mathrm{O}$ ) and slight fall in $\mathrm{SpO}_{2}$ after delivery (Table 1) in the first patient. This can be explained by the autotransfusion which occurs due to contraction of the uterus. Additional furosemide was administered to counter this effect.

\section{CONCLUSION}

A combination of etomidate with low-dose fentanyl and diltiazem for HR control helps in achieving the tight balance between preservation of maternal hemodynamics and minimizing neonatal respiratory depression in patients undergoing combined CS with MVR.

\section{CLINICAL SIGNIFICANCE}

A thorough knowledge of the pathophysiology of both RHD and pregnancy, prudent choice of anesthesia technique, along with close maternal and fetal monitoring and a multidisciplinary approach can lead to a successful outcome.

\section{REFERENCES}

1. Hiralal K, Snehamay C. Pregnancy complicated by maternal heart disease: a review of 281 women. J Obstet Gynecol India 2012 May-Jun;62(3):301-306.

2. Siu SC, Sermer M, Colman JM, Alvarez AN, Mercier LA, Morton BC, Kells CM, Bergin ML, Kiess MC, Marcotte F, et al. Prospective multicenter study of pregnancy outcomes in women with heart disease. Circulation 2001 Jul;104(5):515-521.

3. Bhatla N, Lal S, Behera G, Kriplani A, Mittal S, Agarwal N, Talwar KK. Cardiac disease in pregnancy. Int J Gynecol Obstet 2003 Aug;82(2):153-159.

4. Nishimura RA, Otto CM, Bonow RO, Carabello BA, Erwin JP 3rd, Guyton RA, O'Gara PT, Ruiz CE, Skubas NJ, Sorajja P, et al. 2014 AHA/ACC guideline for the management of patients with valvular heart disease: executive summary: a report of the American college of cardiology / American heart association task force on practice guidelines. J Am Coll Cardiol 2014 Jun;63(22):2438-2488.

5. European Society of Gynecology (ESG); Association for European Paediatric Cardiology (AEPC); German Society for Gender Medicine (DGesGM); Regitz-Zagrosek V, Blomstrom Lundqvist C, Borghi C, Cifkova R, Ferreira R, Foidart JM, Gibbs JS, Gohlke-Baerwolf C, Gorenek B, Iung B, et al. ESC guidelines on the management of cardiovascular diseases during pregnancy: the Task Force on the Management of Cardiovascular Diseases during Pregnancy of the European Society of Cardiology (ESC). Eur Heart J 2011 Dec;32(24):3147-3197.

6. Born D, Martinez EE, Almeida PA, Santos DV, Carvalho AC, Moron AF, Miyasaki CH, Moraes SD, Ambrose JA. Pregnancy in patients with prosthetic heart valves: the effects of anticoagulation on mother, fetus, and neonate. Am Heart J 1992 Aug;124(2):413-417.

7. Cacciotti L, Passaseo I. Management of atrial fibrillation in pregnancy. J Atr Fibrillation 2010 Oct;3(3):295.

8. Orme RM, Grange CS, Ainsworth QP, Grebenik CR. General anaesthesia using remifentanil for caesarean section in parturients with critical aortic stenosis: a series of four cases. Int J Obstet Anesth 2004 Jul;13(3):183-187.

9. Frölich MA, Burchfield DJ, Euliano TY, Caton D. A single dose of fentanyl and midazolam prior to Cesarean section have no adverse neonatal effects. Can J Anaesth 2006 Jan;53(1):79-85.

10. Datt V, Tempe DK, Virmani S, Datta D, Garg M, Banerjee A, Tomar AS. Anesthetic management for emergency cesarean section and aortic valve replacement in a parturient with severe bicuspid aortic valve stenosis and congestive heart failure. Ann Card Anaesth 2010 Jan-Apr;13(1):64-68.

11. Birincioglu CL, Küçüker SA, Yapar EG, Yildiz U lku, Ulus AT, Yamak B, Katircioglu SF, Tasdemir O. Perinatal mitral valve interventions: a report of 10 cases. Ann Thorac Surg 1999 May;67(5):1312-1314.

12. Tempe DK, Virmani S, Tempe A, Sharma JB, Datt V, Nigam M. Anaesthetic management of emergency caesarean section and reoperative mitral valve replacement in a 32 weeks parturient: a case report. Ann Card Anaesth 2002 Jan;5(1):63-67.

13. Bilehjani E, Kianfar AA, Toofan M, Fakhari MS. Anesthesia with etomidate and remifentanil for cesarean section in severe peripartum cardiomyopathy. Middle East J Anesthesiol 2008 Jun;19(5):1141-1149. 